\title{
Hubungan Antara Pengetahuan Ibu Tentang Oral Hygiene Dengan Kejadian MoniliasisPada Neonatus di Poli Tumbuh Kembang RSUD Sidoarjo
}

\author{
Ira Puspita Sari', Damarati Azaria ${ }^{2}$ \\ 1. Mahasiswa Program Studi D-III Kebidanan Universitas PGRI Adi Buana Surabaya \\ 2. Tenaga Pengajar Program Studi D-III Kebidanan Universitas PGRI Adi Buana Surabaya
}

\begin{abstract}
ABSTRAK
Di dapatkan bayi berusia 0 - 28 hari yang kontrol di poli tumbuh kembang RSUD Sidoarjo mengalami moniliasis. Faktor yang dapat mempengaruhi terjadinya moniliasis adalah pengetahuan ibu tentang perawatan bayi terutama oral hygiene. Penelitian ini bertujuan untuk mengetahui Hubungan Pengetahuan Ibu Tentang Oral Hygiene dengan Kejadian Moniliasis pada Bayi di Poli Tumbuh Kembang RSUD Sidoarjo.

Desain penelitian yang digunakan adalah analitik korelasional dengan pendekatan cross sectional. Populasi pada penelitian ini adalah semua ibu yang mempunyai bayi dan berkunjung di Poli Tumbuh Kembang RSUD Sidoarjo pada bulan Juni 2013 sebanyak 64 responden dengan menggunakan Purposive sampling didapatkan sampel sebesar 30 responden.

Penelitian ini menggunakan alat ukur kuisioner. Berdasarkan uji statistik dengan menggunakan Continuity correction $\left(\mathrm{x}^{2}\right)$ untuk mengetahui hubungan antara pengetahuan ibu tentang oral hygiene dengan kejadian moniliasis pada neonatus didapatkan $\chi^{2}: 13,040 p: 0,001$ dan tingkat kemaknaan $\alpha$ : 0,05 maka $\mathrm{P}<\alpha$ sehingga Ho ditolak dan $\mathrm{H}_{1}$ diterima, yang artinya ada hubungan antara pengetahuan ibu tentang oral hygiene dengan kejadian moniliasis pada neonatus. Hal ini dibuktikan oleh 12 responden (40\%) yang mempunyai pengetahuan baik tentang oral hygiene. Dan angka kejadian moniliasis pada bayi hanya sebagian kecil yaitu terjadi pada 8 responden $(26,7 \%)$.

Saran dari peneliti diharapkan para ibu harus lebih memperhatikan perilaku kesehatan yang diberikan kepada bayinya dengan menambah pengetahuan tentang personal hygiene terutama oral hygiene serta berani mengaplikasikan pada bayinya.
\end{abstract}

Kata Kunci : Moniliasis, Oral Hygiene, Neonatus

\section{PENDAHULUAN}

Gangguan

integumentpadaneonatusadalah

sistem

suatu

gangguan yang berhubungan dengan jaringan penutup permukaan tubuh,seperti membran mukosa dan kulit,yang sering terjadi dan bersifat relatif ringan. Gangguan ini sering di alami oleh bayi dan anak.Meskipun sifatnya relatif ringan,apabila tidak di tangani secara serius,maka hal tersebut dapat memperburuk kondisi kesehatan bayi dan anak. Gangguan sistem integument yang sering terjadi pada masaneonatusadalah moniliasis.

Status sosial ekonomi orang tua tidak menjamin bayinya untuk tidak mengalami gangguan integument, apabila orang tuanya tidak mengetahui cara merawat bayi yang benar.

Kesehatan dan kebersihan mulut bayi sangat penting untuk dijaga dan diperhatikan oleh para orang tua, sebab mukosa mulut bayi masih sangat tipis sehinggamasalah mulut akan lebih rentan terjadi pada bayi.Moniliasis merupakan penyakit yang terjadi di dalam rongga mulut yang bisa menyerang siapa saja tidak hanya pada orang dewasa tetapi juga pada bayi maupun anak. Moniliasis ini menyerupai bercak-bercak putih dan lebih sering timbul di lidah, bibir, pipi bagian dalam (mucosa) dan tenggorokan (Nursalam dkk, 2005, hal 97-98).

Umumnya moniliasis yang terjadi pada bayi disebabkan oleh jamur sedangkan pada anak dan balita disebabkan oleh trauma dan juga jamur. Penyebab yang paling umum pada penyakit ini adalah candida albicans. Sariawan atau candidiasis oral adalah infeksi supersialis membran mucosa yang mengenai sekitar 2-5\% neonatus normal. Bayi mendapat jamur ini dari ibunya pada saat persalinan yang terinfeksi candida.( Robin Dompas, 2011, hal 111). Sariawan (moniliasis) ini juga sering dijumpai pada bayi dan anak kecil yang minum susu dengan botol / dot atau anak yang mengisap 
dot kempeng (fopspeen) yang tidak bersih.Adanya sisa susu dalam mulut bayi setelah minum juga dapat menjadi penyebab stomatitis jika ada bakteri di dalam mulutnya. (Ngastiyah, 2005, hal 222 \& 223). Di Poli Tumbuh Kembang RSUD Sidoarjo berdasarkan pada buku register bayi dan balita bulan Januari 2013, terdapat 60 bayi usia 0-28 hari. Dari jumlah tersebut dilakukan pemeriksaan rongga mulut ditemukan 15 bayi mengalami moniliasis dan 25 bayi mengalami white coated tongue (warna putih di lidah karena sisa susu dan mudah di bersihkan). Kendati hal ini bukan penyakit yang mematikan namun jika tidak diatasi akan menimbulkan ketidaknyamanan pada bayi. Bayi akan terus menurus menangis dan gelisah akibat nyeri yang ditimbulkan oleh sariawan (moniliasis) tersebut. Akibatnya bayi menjadi tidak mau minum susu ataupun menyusuibunya, hal ini tentunya akan mengurangi asupan cairan dan kalori yang dibutuhkan oleh bayi. (Ngastiyah, 2005, hal 222). Keadaan ini pasti akan mengkhawatirkan para orang tua. Masalah ini masih dapat kita hindari dengan cara membersihkan mulut bayi setelah selesai diberi minum susu formula ataupun ASI dan selalu memperhatikan kebersihan semua perlengkapan minum bayi, oleh sebab itu para orang tua harus memperahatikan keadaan ini terutama dalam membersihkan dan merawat mulut bayi agar tetap sehat.Berdasarkan data pendahuluan yang dilakukandi Poli Tumbuh Kembang RSUD Sidoarjo pada saat kontrol ditemukan adanya beberapa bayi mengalami moniliasis di sekitar lidahnya. Dari 10 ibu yang mempunyai bayi usia 0-7 hari, 2 ibu mengetahui tentang oral hygiene dan melakukan pada bayinya, 5 ibu mengetahui tentang oral hygiene tapi tidak berani melakukannya dan 3 lainnya tidak tahu tentang oral hygiene.Dari latar belakang tersebut,peneliti tertarik untuk melakukan penelitian "bagaimana hubungan antara pengetahuan ibu tentang oral hygiene dengan kejadian moniliasis pada neonatus di poli tumbuh kembang RSUD Sidoarjo".Berdasarkan latar belakang permasalahan maka rumusan masalah dalam penelitian ini adalah "Adakah Hubungan Antara Pengetahuan lbu Tentang Oral Hygiene Dengan Kejadian moniliasis Pada Neonatus di Poli Tumbuh Kembang RSUD Sidoarjo ?". Tujuan umum penelitian ini adalah mengetahui hubungan antara pengetahuan ibu tentang oral hygiene (kebersihan mulut) dengan kejadian moniliasis pada neonatus di Poli
Tumbuh Kembang RSUD Sidoarjo. Tujuan khusus dari penilitian ini adalah : a.) Mengidentifikasi pengetahuan ibu tentang oral Hygiene (kebersihan mulut) pada neonatus di Poli tumbuh kembang RSUD Sidoarjo; b.) Mengidentifikasi neonatus yang mengalami moniliasis; c.) Menganalisis hubungan oral hygiene dengan kejadian moniliasis pada neonatus di Poli Tumbuh Kembang RSUD Sidoarjo.Dengan di lakukan penelitian ini di harapkan dapat memberikan manfaat bagi pihak yang berkepentingan antara lain : 1.) Bagi tempat penelitian (Poli Tumbuh Kembang RSUD Sidoarjo), sebagai bahan masukan bagi para petugas kesehatan yang terkait agar lebih meningkatkan pelayanan kesehatan terutama dalam upaya promotif terhadap ibu-ibu dalam memelihara kesehatan mulut bayinya; 2.) Bagi responden, sebagai tambahan pengetahuan sehingga dapat menambah pengetahuan ibu tentang pentingnya melakukan oral hygiene (kebersihan mulut) dalam mengatasi terjadinya moniliasis pada bayi maupun anak balita serta meningkatkan perilaku hidup sehat terutama dalam memelihara kesehatan mulut bayi dan anak; 3.) Bagi peneliti, sebagai pengalaman dalam menerapkan mata kuliah metode penelitian dan menambah pengetahuan tentang moniliasis pada Neonatus; 4.) Bagi Institusi Pendidikan, penelitian ini dapat di gunakan sebagai informasi tentang tingkat pengetahuan ibu tentang oral hygiene (kebersihan mulut) dengan kejadian moniliasis periode tahun 2013-2014.

\section{BAHAN DAN METODE}

Desain penelitian yang digunakan dalam penelitian ini adalah analitik korelasi, dengan pendekatan cross sectional dimana dalam penelitian ini menekankan pada pengukuran atau observasi data variabel independent dan variabel dependent. Dengan studi ini akan diperoleh prevalensi atau efek dari fenomena (variabel dependent) dihubungkan dengan penyebab (variabel independent). Penelitian dilaksanakan pada 1 Juni - 30 Juni 2013. Pengambilan data awal untuk data pendahuluan dilakukan pada bulan Februari2013di poli tumbuh kembang RSUD Sidoarjo.Populasi yang digunakan adalah seluruh ibu yangmempunyai bayi usia 0-28 hari yang datang kontrol di poli tumbuh kembang RSUD Sidoarjo, yaitu dengan jumlah 64 ibu. Sampel yang digunakan adalah sebagian ibu yang mempunyai bayi usia $0-28$ hari yang 
datang kontrol di poli tumbuh kembang RSUD Sidoarjo, yaitu 30 ibu, pada penelitian ini sampel yang diambil dari populasi yang memenuhi kriteria inklusi. Kriteria Inklusi untuk penelitian ini adalah : a.) lbu yang mempunyai bayi usia 0-28 hari yang datang kontrol di poli tumbuh kembang RSUD Sidoarjo; b.) lbu yang bersedia menjadi responden dan telah menandatangani persetujuan menjadi responden; c.) Ibu yang dapat membaca dan menulis. Penelitian ini menggunakan metode Purposive Sampling. Purposive Sampling adalah suatu teknik penetapan sampel diantara populasi sesuai dengan yang dikehendaki peneliti sehingga sampel tersebut dapat mewakili karakteristik populasi yang telah dikenal sebelumnya.Dalam penelitian ini ada dua variabel yaitu variabel bebas atau variabel independen dan variabel terikat atau variabel dependen. Variabel independen (variabel bebas) dalam penelitian ini adalah pengetahuan ibu tentang oral hygiene dengan menggunakan kuesioner dan variabel dependen (variabel terikat) adalah kejadian moniliasis pada neonatus dengan melakukan observasi pada mulut bayi usia $0-28$ hari.Definisi operasional adalah mendefinisikan variabel secara operasional berdasarkan karakteristik yang diamati, memungkinkan peneliti untuk melakukan observasi atau pengukuran secara cermat terhadap suatu objek atau fenomena. Definisi operasional ditentukan berdasarkan parameter yang dijadikan ukuran dalam penelitian. Sedangkan cara pengukuran merupakan cara dimana variabel diukur dan ditentukan karakteristiknya (Notoatmojo 2011).Instrumen dalam penelitian ini adalah berupa data primer. Pengumpulan data dalampenelitian terdiri dari pengumpulan data primer diperoleh dengan cara menyebarkan kuesioner pada ibu yang mempunyai bayi dan memenuhi kriteria inklusi dan menandatangani persetujuan menjadi responden, dan melakukan observasi pada mulut bayi usia 0-28 hari.Hasil pengumpulan data yang terkumpul selanjutnya dilakukan pengolahan data sebagai berikut : a.) Editing (koreksi), merupakan upaya untuk memeriksa kembali kebenaran data yang dikumpulkan atau diperoleh (Notoatmojo 2011). Setelah kuesioner dibagikan dan diisi maka selanjutnya dilakukan editing untuk memeriksa kembali kelengkapan data; b.) Coding (kode), merupakan kegiatan memberikan kode numerik (angka) terhadap data yang terdiri atas beberapa kategori berdasarkan nomor urut responden (Notoatmojo 2011); c.) Skoring (penilaian), menentukan skor atau nilai dari item pertanyaan setelah data lengkap. Setelah data terkumpul maka dilakukan editing skoring untuk menentukan presentase dengan cara ini dapat diketahui prosentase dari masing-masing data yang dinilai dengan rumus :

$$
\begin{aligned}
& P=\frac{F}{N} \times 100 \% \\
& \text { Keterangan : } \\
& \mathrm{P}: \text { Prosentase } \\
& \mathrm{F}: \text { Jumlah Jawaban Benar } \\
& \mathrm{N}: \text { Jumlah skor maksimal }
\end{aligned}
$$

d.) Tabulating (tabulasi), Tabulasi adalah memasukan data kedalam tabel dan mengatur semua angka sehingga dapat dihitung sebagai kategori (Nasir, 2003).

Analisa data dalam penelitian ini dilakukan menggunakan analisis nonparametris. Analisa ini dilakukan untuk menguji independensi antara suatu variabel terhadap variabel lainnya. Analisis yang digunakan adalah Chisquare (kai kuadrat test) dengan $\alpha: 5 \%$

$$
X^{2}=\sum_{i=1}^{k} \frac{(0 i-E i)^{2}}{E i}
$$

Keterangan :

Oi : nilai pengamatan yang diperoleh pada

kategori yang ke i

$\mathrm{Ei}$ : nilai harapan (expected value) pada

kategori yang ke $\mathrm{i}$

$\sum_{i=1}^{k}$ : jumlah kategori yang diamati

\section{HASIL DAN PEMBAHASAN}

Berikut ini akan dijelaskan mengenai hasil dan analisis dari penelitian hubungan pengetahuan ibu tentang oral hygiene (kebersihan mulut) dengan kejadian moniliasis pada neonatus di poli tumbuh kembang RSUD Sidoarjo. Pengumpulan data di lakukan dengan cara membagikan kuesioner pada ibu-ibu yang mempunyai bayi usia $0-28$ hari yang datang kontrol di poli tumbuh kembang RSUD Sidoarjo, dan sudah menanda tangani lembar persetujuan menjadi responden serta melakukan observasi pada mulut bayi usia 0 28 hari (apakah terjadi moniliasis atau tidak) pada 1 Juni - 30 Juni 2013.

\section{Data Umum}


Dalam data umum ini akan disajikan karakteristik responden

berdasarkanpendidikan.

\begin{tabular}{cccc}
\hline No & Pendidikan & Frekuensi & $\begin{array}{c}\text { Persentase } \\
\%\end{array}$ \\
\hline 1 & $\begin{array}{c}\text { Rendah (SD } \\
\text { ) }\end{array}$ & 5 & 16,6 \\
2 & $\begin{array}{c}\text { Menengah } \\
\text { (SMP) }\end{array}$ & 11 & 36,6 \\
3 & $\begin{array}{c}\text { Tinggi (SMA } \\
\text { - PT) }\end{array}$ & 14 & 46,6 \\
\hline & Total & 30 & 100 \\
\hline
\end{tabular}

Tabel 1 - Distribusi frekuensi ibu yang mempunyai bayi usia $0-28$ hari berdasarkan tingkat pendidikan di Poli Tumbuh Kembang RSUD Sidoarjo Pada 1 Juni-30 Juni 2013.

Tabel 1. menunjukkan bahwa dari 30 ibu yang mempunyai bayi usia 0-28 hari sebagian besar berlatar belakang pendidikan tinggi yaitu $46,6 \%$ (14 ibu).

\section{Data Khusus}

Data ini akan menjelaskan tentang pengaruh antara variabel independen (pengethuan ibu tentang oral hygiene) dan variabel dependen (kejadin moniliasis)yang bisa menjelaskan bagaimana tingkat pengetahuan ibu tentang oral hygiene dengan kejadian moniliasis di Poli Tumbuh Kembang RSUD Sidoarjo pada 1 Juni - 30 Juni 2013.

\begin{tabular}{cccc}
\hline No & $\begin{array}{c}\text { Kriteria } \\
\text { tingkat } \\
\text { pengetahuan }\end{array}$ & Frekuensi & $\begin{array}{c}\text { Persentase } \\
\%\end{array}$ \\
\hline 1 & Kurang & 8 & 26,67 \\
2 & Cukup & 10 & 33,3 \\
3 & Baik & 12 & 40 \\
\hline & Total & 30 & 100 \\
\hline
\end{tabular}

Tabel 2 - Distribusi frekuensi ibu yang mempunyai bayi usia $0-28$ hari berdasarkan tingkat pengetahuan di Poli Tumbuh Kembang RSUD Sidoarjo Pada 1 Juni -30 Juni 2013

Tabel 2. menunjukkan bahwa dari 30 responden yang mempunyai bayi usia $0-28$ hari memiliki pengetahuan baik yaitu $40 \%$ (12 ibu).

\begin{tabular}{cccc}
\hline No & $\begin{array}{c}\text { Kejadian } \\
\text { Moniliasis }\end{array}$ & Frekuensi & $\begin{array}{c}\text { Persentase } \\
\%\end{array}$ \\
\hline 1 & $\begin{array}{c}\text { Terjadi } \\
\text { Moniliasis }\end{array}$ & 8 & 26,7
\end{tabular}

Tabel 4 - Hubungan antara pengetahuan ibu tentang oral hygiene dengan kejadian moniliasis pada neonatus di Poli tumbuh kembang RSUD Sidoarjo Pada 1 Juni - 30 Juni 2013

Tabel 4 menunjukkan dari 12 orang (40\%) ibu yang memiliki pengetahuan baik, mayoritas anaknya tidak mengalami kejadian moniliasis yaitu $36,7 \%$ (11 orang). Begitu juga dengan ibu yang memiliki pengetahuan cukup, mayoritas anaknya tidak mengalami kejadian moniliasisyaitu $30 \%$ (9 orang). Sedangkan ibu yang memiliki pengetahuan kurang, anaknya mengalami kejadian moniliasisyaitu $20 \%$ (6 orang).

Untuk memperkuat tabulasi di atas, maka langkah-langkah uji chi-square adalah sebagai berikut :

$\mathrm{H}_{0}=$ Tidak ada hubungan antara pengetahuan ibu tentang oral hygiene dengan kejadian moniliasis pada neonatus.

$\mathrm{H}_{1}=$ Ada hubungan antara pengetahuan ibu tentang oral hygiene dengan kejadian moniliasis pada neonatus.

Nilai uji chi-square yang dihasilkan : 
pengetahuan ibu * kejadian oral trush Crosstabulation

\begin{tabular}{|c|c|c|c|c|c|}
\hline & \multicolumn{2}{|c|}{ kejadian oral trush } & \multirow[b]{2}{*}{ Total } \\
\hline & & & tidak terjad & terjadi & \\
\hline \multirow{9}{*}{$\begin{array}{l}\text { pengetahuar } \\
\text { ibu }\end{array}$} & kurang & Count & 2 & 6 & 8 \\
\hline & & Expected Cou & 5.9 & 2.1 & 8.0 \\
\hline & & $\%$ of Total & $6.7 \%$ & $20.0 \%$ & $26.7 \%$ \\
\hline & cukup & Count & 9 & 1 & 10 \\
\hline & & Expected Cou & 7.3 & 2.7 & 10.0 \\
\hline & & $\%$ of Total & $30.0 \%$ & $3.3 \%$ & $33.3 \%$ \\
\hline & baik & Count & 11 & 1 & 12 \\
\hline & & Expected Cou & 8.8 & 3.2 & 12.0 \\
\hline & & $\%$ of Total & $36.7 \%$ & $3.3 \%$ & $40.0 \%$ \\
\hline \multirow{3}{*}{\multicolumn{2}{|c|}{ Total }} & Count & 22 & 8 & 30 \\
\hline & & Expected Cou & 22.0 & 8.0 & 30.0 \\
\hline & & $\%$ of Total & $73.3 \%$ & $26.7 \%$ & $100.0 \%$ \\
\hline
\end{tabular}

$$
\begin{gathered}
\chi^{2}=\quad \sum_{i=1}^{k} \frac{(0 i-E i)^{2}}{E i} \\
= \\
\frac{(2-5,9)^{2}}{5,9}+\frac{(6-2,1)^{2}}{21}+\frac{(9-7,3)^{2}}{7,3}+\frac{(1-27)^{2}}{27}+\frac{(1-8,8)^{2}}{8,8}+\frac{(1-3,2)^{2}}{3,2}= \\
13,040
\end{gathered}
$$

Berdasarkan uji statistik dengan menggunakan Continuity correction $\left(\mathrm{x}^{2}\right)$ untuk mengetahui hubungan antara pengetahuan ibu tentang oral hygiene dengan kejadian moniliasis pada neonatus didapatkan $\chi^{2}: 13,040 p: 0,001$ dan tingkat kemaknaan $\alpha: 0,05$ maka $P<\alpha$ sehingga Ho ditolak dan $\mathrm{H}_{1}$ diterima, yang artinya ada hubungan antara pengetahuan ibu tentang oral hygiene dengan kejadian moniliasis pada neonatus di Poli Tumbuh Kembang RSUD Sidoarjo, sehingga hipotesis penelitian ini teruji kebenarannya.

Berdasarkan table 2 dari hasil penelitian yang telah dilaksanakan di Poli Tumbuh Kembang RSUD Sidoarjo didapatkan hasil bahwa pengetahuan ibu tentang oral hygiene (kebersihan mulut) sebagian besar adalah kategori baik sebanyak 12 ibu (40 $\%)$.

Pengetahuan juga dapat di pengaruhi oleh tingkat pendidikan. Makin tinggi tingkat pendidikan seseorang maka makin mudah dalam menerima informasi, sehingga semakin banyak pengetahuan yang dimiliki. Sebaliknya pendidikan yang kurang akan menghambat perkembangan sikap seseorang terhadap nilai-nilai yang baru dikenal, selain pendidikan tingkat pengetahuan juga di pengaruhi oleh status ekonomi, pengalaman, informasi dan pergaulan. Tetapi dalam penelitian ini faktor yang paling dominan adalah tingkat pendidikan.

Dalam penelitian ini tingkat pengetahuan ibu adalah kategori baik karena ibu mempunyai latar belakang pendidikan tinggi. Pengetahuan itu terdiri dari sejumlah fakta dan teori yang memungkinkan seseorang untuk dapat memecahkan masalah yang di

hadapinya. Pengetahuan seseorang dapat di peroleh baik dari pengalaman langsung maupun melalui pengalaman orang lain. Apabila seseorang mempunyai pengetahuan baik maka akan mudah dalam menerima informasi.

Hasil penelitian ini membuktikan bahwa pendidikan berbanding lurus dengan pengetahuan seseorang. Tingkat pendidikan yang tinggi akan menjadikan seseorang memiliki pengetahuan yang lebih baik. Khususnya dalam penelitian ini mengenai pengetahuan ibu tentang oral hygiene. Semakin tinggi pendidikan ibu, maka pengetahuan ibu tentang oral hygiene (kebersihan mulut) akan menjadi lebih baik. Berdasarkan tabel 3 dapat disimpulkan hampir seluruhnya $(73,3 \%)$ atau sebanyak 22 responden yang memiliki bayi tidak menderita moniliasis, dan 8 (26,7 \%) responden yang mempunyai bayi mengalami moniliasis. Moniliasis merupakan inflamasi dan ulserasi pada membrane mukosa mulut. Sisa susu dan ASI yang menempel pada mulut bayi dapat menimbulkan moniliasis atau sariwan pada mulut bayi. Penyebab terjadinya moniliasis pada umumnya adalah jamur candida albicans yang ditularkan melalui vagina ibu yang terinfeksi selama persalinan (saat bayi baru lahir) atau transmisi melalui botol susu dan putting susu yang tidak bersih serta adanya sisa susu dalam mulut bayi setelah minum yang tidak di bersihkan dapat menjadi moniliasis. Moniliasis kadang sulit dibedakan dengan sisa susu, terutama pada bayi yang mendapatkan susu formula. Sisa susu yang berupa endapan putih tebal pada lidah bayi dapat dibersihkan dengan kapas lidi yang dibasahi dengan air hangat.

Moniliasis ini juga harus dibedakan dengan stomatitis.Stomatitis merupakan inflamasi dan ulerasi pada membran mukosa mulut. Anak yang mengalami stomatitis biasanya tidak mau makan atau minum.(M. Scharin, 1994:448). Sebagian besar bayi ada yang menampakkan gejala, tetapi ada bayi tidak menimbulkan gejala. Gejala tersebut antara lain :bercak-bercak putih didalam bibir dan pipi bagian dalam nampak seperti gumpalan keju dan sulit dilepaskan, bayi kadangkadang menolak untuk minum susu atau menyusu.Keadaan ini bisa terjadi pada semua bayi apabila ibu tidak melakukan perawatan bayi sehari-hari terutama 
perawatan mulut dengan benar. Pengaruh dari bayi yang mengalami moniliasis adalah dapat mempengaruhi asupan nutrisi. Asupan nutrisi yang kurang dapat mengakibatkan status gizi pada bayi kurang.Salah satu cara yang dapat dilakukan untuk mencegah terjadinya moniliasis adalah dengan melakukan oral hygiene.

Berdasarkan tabel 4 menunjukkan dari 12 orang (40 \%) ibu yangmemiliki pengetahuan baik, mayoritas anaknya tidak mengalami kejadian moniliasis yaitu 11 orang (36,7\%). Begitu juga dengan ibu yang memiliki pengetahuan cukup, mayoritas anaknya tidak mengalami kejadian moniliasisyaitu $30 \%$ (9 orang). Sedangkan ibu yang memiliki pengetahuan kurang,anaknya mengalami kejadian moniliasisyaitu 6 orang (20\%).Berdasarkan uji statistik dengan menggunakan Continuity correction $\left(\mathrm{x}^{2}\right)$ untuk mengetahui hubungan antara pengetahuan ibu tentang oral hygiene dengan kejadian moniliasis pada neonatesdidapatkan $\chi^{2}: 13,040 \quad p: 0,001$ dan tingkat kemaknaan $\alpha: 0,05$ maka $P<\alpha$ sehingga $\mathrm{Ho}$ ditolak dan $\mathrm{H}_{1}$ diterima, yang artinya ada hubungan antara pengetahuan ibu tentang oral hygiene dengan kejadian moniliasis pada neonatus di Poli Tumbuh Kembang RSUD Sidoarjo.Moniliasis pada bayi dapat dicegah, salah satunya dengan cara melakukan oral hygiene. Oral hygiene (kebersihan mulut) merupakan salah satu upaya untuk mencegah timbulnya berbagai masalah dimulut dan untuk menghindari pertumbuhan bakteri dan jamur dimulut.Seseorang dapat melakukan oral hygiene dengan baik jika memiliki pengetahuan tentang oral hygiene yang baik. Terutama pengetahuan tentang oral hygiene (kebersihan mulut) untuk mencegah timbulnya berbagai masalah dimulut serta untuk menghindari pertumbuhan bakteri dan jamur dimulut yang disebabkan oleh sisasisa susu yang menempel dimulut bayinya sehingga semakin baik pengetahuan ibu tentang oral hygiene (kebersihan mulut) maka akan semakin jarang kejadian moniliasis pada bayi.

\section{SIMPULAN DAN SARAN}

Berdasarkan hasil penelitian yang telah dilaksanakan dapat dirumuskan kesimpulan sebagai berikut: 1.) Didapatkan hasil bahwa pengetahuan ibu tentang oral hygiene (kebersihan mulut) sebagian besar adalah kategori baik; 2.) Di dapatkan hasil bahwa hampir seluruhnya ibu yang memiliki bayi tidak menderita moniliasis; 3.) Ada hubungan antara pengetahuan ibu tentang oral hygiene (kebersihan mulut) dengan kejadian moniliasis pada neonatus di Poli Tumbuh Kembang RSUD Sidoarjo.

Bila dilihat dari manfaat oral hygiene yang sangat penting untuk kesehatan mulut bayi maka peneliti menyarankan : 1.) Bidan lebih meningkatkan KIE perawatan bayi seharihari khususnya tentang oral hygiene (kebersihan mulut); 2.) Ibu yang mempunyai bayi diharapkan dapat melakukan pemeliharaan kesehatan secara mandiri tentang perawatan bayi sehari-hari khususnya tentang oral hygiene (kebersihan mulut ).

\section{DAFTAR PUSTAKA}

Budiman dan Agus Riyanto (2013). Kapita Selekta Kuesioner. Salemba Medika, Jakarta.

Casiglia, Jeffrey M. (2010). Aphthous Stomatitis. http:// emedicine. Medscape.Com. Diakses tanggal 20 Februari 2013.

dr-suparyanto (2012). Journal-keperawatanhubungan-oral-hygiene-dengan

stomatitis $2 \mathrm{html}$. di akses tanggal 13 maret 2013 jam 20.00 wib. http//blogspot.com

Kementrian Kesehatan, R.I (2011). Buku Saku Pelayanan Kesehatan Neonatal Esensial. Jakarta.

Ngastiyah (2005). Perawatan Anak Sakit. EGC. Jakarta.

Nursalam, dkk (2005). Asuhan Keperawatan Bayi dan Anak. Salemba Medika, Jakarta.

Potter dan Perry (2005). Buku Ajar Fundamental. Edisi 4. EGC. Jakarta.

Robin dompas (2009). Buku Saku Asuhan Neonatus, Bayi, dan Balita. EGC, Jakarta. 
Soekidjo Notoatmojo (2010). Metodologi Penelitian Kesehatan. Rineka Cipta, Jakarta.

Sonny, K dan Michael, D (2001). IImu Pengetahuan. Kanisius. Yogyakarta.

Sudarti dan Endang K (2010). Asuhan Kebidanan Neonatus, Bayi, dan Anak Balita. Nuha Medika. Yogyakarta.

Wafi, N (2010). Asuhan Neonatus, Bayi, dan Balita. Fitramaya. Yogyakarta. 